\title{
An Evidence-Based Analysis of Simultaneous Pancreas-Kidney and Pancreas Transplantation Alone
}

\author{
Nicolas Demartines, Marc Schiesser \\ and Pierre-Alain Clavien*
}

Department of Visceral and Transplant Surgery, University

Hospital, Zurich, Switzerland

* Corresponding author: Pierre-Alain Clavien, clavien@chir.unizh.ch

\begin{abstract}
While pancreas transplantation has evolved within two decades from a frustrating and poorly-accepted therapeutic option to a highly successful procedure, the respective benefits of the successive surgical and immunosuppressive developments have remained unclear. The aim of this study was to determine using an evidence-based methodology, which novel approaches have contributed to the current results and whether pancreas transplantation is cost-effective. Out of 2481 articles, 102 analyzed either surgical or immunosuppressive aspects of pancreas transplantation. Urological complications were more frequent in bladder over enteric drainage (range: $62-63 \%$ vs. $12-$ $20 \%, p=0.0001$ ), but without significant difference in patient or graft survival. Portal drainage was associated with a trend toward fewer complications and better hyperinsulinemia control over systemic drainage in retrospective studies. Immunosuppression combining induction therapy, a calcineurin inhibitor, mycophenolate mophetil (MMF) and corticosteroids were associated with a $\mathbf{4 0} \%$ decreased incidence of rejection $(p=0.01)$ and an increase in graft survival above $90 \%$ at 1 year $(p<0.05)$. Pancreas transplantation is highly cost-effective compared to conservative alternatives. We conclude that despite a paucity of large studies, enteric drainage should be recommended but the benefits of portal venous drainage remain debated. Quadruple immunosuppression protocols including induction therapy should be the standard regimen.
\end{abstract}

Key words: Drainage techniques, evidence-based medicine, immunosuppression, pancreas transplantation alone, simultaneous pancreas kidney transplantation

Received 13 April 2005, revised 29 June 2005 and accepted for publication 11 July 2005

\author{
Introduction
}

Kelly et al. performed the first pancreas transplantation in 1966 at the University of Minnesota (1). Until the early 80s, the reported worldwide series were characterized by poor success rates due to a high incidence of surgical complications and irreversible rejection (2-5). From the mid-1980s, innovative technical and anti-rejection strategies enabled significant improvement in graft function and survival. The introduction of exocrine bladder drainage was associated with a decreased incidence of post-operative complications mostly related to earlier detection of rejection through monitoring of urine amylase levels (6). The availability of $\mathrm{Cy}$ closporin A (CyA) in 1983 undoubtedly further contributed to better graft survival (7). Many recent innovations in pancreas transplantation have contributed to improvements with a 93\% 1-year graft and patient survival rates reported in 2002, by the International Pancreas Transplant Registry (IPTR) $(8,9)$. However, which interventions have provided benefits remains controversial and no evidence-based recommendation on a surgical procedure or immunosuppression protocol is currently available.

The need to base clinical decisions on the best available scientific evidence is supported by the importance of quality control and cost-containment, as well as the increasing patient interest for the best available treatment. Evidencebased surgery is a modern approach to achieve objective criteria for indications and operation techniques. Alternative therapies such as islet cell transplantation (10) or insulin pump devices as less invasive procedures, may challenge the value of pancreas transplantation in the near future. Therefore, a critical assessment of the current results of pancreas transplantation appears timely.

The aim of this study was to perform an evidence-based analysis of simultaneous pancreas-kidney transplantation (SPK) and pancreas transplantation alone. We assessed the outcome according to the different operation techniques and immunosuppression protocols, and looked at cost-efficiency.

\section{Materials and Methods}

Literature research

An electronic search of the Medline database from 1992 to December 2004 was performed to identify all relevant articles comparing surgical techniques 
and immunosuppression protocols in pancreas transplantation. The following search terms in the medical subject heading, title and abstract were used in various combinations to refine the search: pancreas, transplantation, drainage, bladder drainage, enteric drainage, portal drainage, systemic drainage, immunosuppression and cost analysis. In addition, we performed manual cross-referencing to identify further articles. All studies that compared different surgical techniques and immunosuppression regimens in SPK were included. Furthermore, we included all articles on cost analysis and pancreas transplantation alone.

Besides the Medline database, another important source of information about pancreas transplantation since 1980 is the International Pancreas Transplant Registry (IPTR), held at the University of Minnesota (8). The database is said to sample about $95 \%$ of all pancreas transplantations performed worldwide, but its value is somewhat limited due to the voluntary self-declaration nature of the data collection. The registry date was used in the present analysis only for epidemiologic information.

\section{Study review and quality grading}

All studies were reviewed independently by two of the authors (ND and MS) as requested in proper evidence-based analysis (11). Discrepancy between the reviewers was resolved by consensus. We included only published full-length papers in English. Review articles, registry data, abstracts and publications of abstract character were excluded. If more than one study by the same group was published with data repetition, only the most recent publication was included in the analysis. The studies were assessed for the following endpoints: 1-year graft survival, 1-year patient survival rate, complication rate, pancreas leakage rate and rejection rate.

All studies were classified according to their level of evidence using the classification proposed by the Oxford Centre for Evidence-based Medicine (Table 1) (11-13). Based on the level of evidence, grades of recommendation (A, B, C, D) were given. Thereby, grade A provides the best and strongest recommendation since it is based on the highest level of evidence (RCT and meta-analysis). The next levels of recommendations are grade $\mathrm{B}$ and C which are used for lower study qualities such as cohort (grade B) and case control studies (grade C). Finally, grade D demonstrates the lowest recommendation since it is based only on expert opinions.

Table 1: Levels of evidence and grade of recommendation proposed by the Oxford Center for Evidence-based Medicine (11)

\begin{tabular}{|c|c|c|}
\hline $\begin{array}{l}\text { Level of } \\
\text { evidence }\end{array}$ & Grading criteria & $\begin{array}{l}\text { Grade of } \\
\text { recommendation }\end{array}$ \\
\hline $1 \mathrm{a}$ & $\begin{array}{l}\text { Systematic review of RCTs } \\
\text { including meta-analysis }\end{array}$ & A \\
\hline $1 b$ & $\begin{array}{l}\text { Individual RCT with narrow } \\
\text { confidence interval }\end{array}$ & A \\
\hline $1 c$ & All or none studies & $\mathrm{B}$ \\
\hline $2 a$ & $\begin{array}{l}\text { Systematic review of cohort } \\
\text { studies }\end{array}$ & $\mathrm{B}$ \\
\hline $2 b$ & $\begin{array}{l}\text { Individual cohort study and low } \\
\text { quality RCT }\end{array}$ & B \\
\hline 2c & Outcome research study & $\mathrm{C}$ \\
\hline $3 a$ & $\begin{array}{l}\text { Systematic review of case-control } \\
\text { studies }\end{array}$ & $\mathrm{C}$ \\
\hline $3 b$ & Individual case-control study & $\mathrm{C}$ \\
\hline 4 & $\begin{array}{l}\text { Case-series, poor quality cohort } \\
\text { and case-control studies }\end{array}$ & $\mathrm{C}$ \\
\hline 5 & Expert opinion & $\mathrm{D}$ \\
\hline
\end{tabular}

$\mathrm{RCT}=$ Randomized controlled trial.

\section{Results}

\section{What material is available for an evidence-based analysis of SPK transplantation?}

A total of 2481 articles were identified in the Medline database. Out of these, 48 were classified as randomized clinical trials (RCT), and 214 as clinical trials according to the national library of medicine. Thirty-six of these publications analyzed the outcome according to various types of surgical drainage techniques, and 66 papers investigated the outcome of different immunosuppression protocols.

Out of the 36 studies assessing various aspects of surgical techniques, 16 had an abstract character only and 6 did not specifically analyze the requested endpoints, and thus were excluded from the analysis. Of the remaining 14 studies, three (14-16) analyzed the impact of venous drainage technique (systemic vs. portal) in enteric-drained patients (Table 3). Two of them were prospective randomized trials $(14,15)$, while the other one was a retrospective study (16). The remaining 11 studies (17-27) analyzed the outcome according to different exocrine drainage (bladder vs. enteric) techniques (Table 2 and 4). They were all ranked level 2b. No prospective randomized trial was identified in this group.

Out of the 66 studies analyzing immunosuppression protocols in SPK transplantation, we established subgroups to evaluate induction therapy (Table 5), calcineurin inhibitors (Table 6), anti-proliferative agents (Table 7) and corticosteroids. Excluded were 29 studies with abstract characters only, 20 reviews and five center reports without comparison with different protocols. Of the selected 10 papers, six were ranked level $1 \mathrm{~b}(14,28-32)$ and four level $2 \mathrm{~b}(23$, 33-35).

While more than 18000 SPK have been performed worldwide $(8,36)$, only few centers have developed a large program (>10 transplants/year). This may explain the paucity of convincing studies available in this field. For example, out of 2481 studies only 48 RCTs could be identified in the Medline database. In addition, most of these studies were published by the same seven centers. As a result, an evidence-based analysis could be based only on a few studies fulfilling the criteria, and the lack of RCTs did not allow us to perform a meta-analysis.

\section{What is the optimal exocrine drainage technique? Bladder or enteric drainage?}

Historically, SPK was associated with a high morbidity due to intra-abdominal sepsis. The anastomotic leaks were believed to be due to duodenal rejection, and the technique was abandoned (7). Bladder drainage was introduced in 1983 in order to reduce the incidence of postoperative technical complications, in particular a reduction in intra-abdominal sepsis (7). This technique allowed the early detection of graft rejection by measuring serial urine 
Demartines et al.

Table 2: Studies on Bladder Drainage versus enteric drainage in SPK

\begin{tabular}{|c|c|c|c|c|c|c|c|}
\hline $\begin{array}{l}\text { Authors, } \\
\text { years }\end{array}$ & Level & Number of Patients & $\begin{array}{l}\text { Urological } \\
\text { complications } \\
(\%)\end{array}$ & $\begin{array}{l}\text { Pancreas } \\
\text { leakage } \\
(\%)\end{array}$ & $\begin{array}{l}\text { Graft } \\
\text { Survival } \\
\text { rate (\%) }\end{array}$ & $\begin{array}{l}\text { Patient } \\
\text { Survival } \\
\text { rate (\%) }\end{array}$ & $\begin{array}{l}\text { Rejection } \\
\text { rate }(\%)\end{array}$ \\
\hline \multirow{4}{*}{$\begin{array}{l}\text { Pirsch et al. } 1998 \\
\text { (22) } \\
\text { Kaufmann et al. } 2000 \\
(23)\end{array}$} & \multirow[t]{2}{*}{$2 b$} & Bladder drainage $(n=48)$ & 63 & 12 & 93 & 98 & NA \\
\hline & & Enteric drainage $(n=78)$ & $20^{*}$ & $5^{*}$ & 93 & 98 & NA \\
\hline & \multirow[t]{2}{*}{$2 b$} & Bladder drainage $(n=50)$ & 48 & NA & 94 & 98 & 28 \\
\hline & & Enteric drainage $(n=50)$ & 37 & NA & 89 & 97 & 16 \\
\hline \multirow{2}{*}{$\begin{array}{l}\text { Sollinger et al. } 1998 \\
\text { (24) }\end{array}$} & \multirow[t]{2}{*}{$2 b$} & Bladder drainage $(n=388)$ & 62 & 17 & 87.6 & 96.1 & 45 \\
\hline & & Enteric drainage $(n=112)$ & $12^{*}$ & 5 & 87.1 & 97.7 & 39 \\
\hline \multirow{2}{*}{$\begin{array}{l}\text { Sutherland et al. } 2001 \\
\text { (25) }\end{array}$} & \multirow[t]{2}{*}{$2 b$} & Bladder drainage $(n=136)$ & NA & NA & 82 & 92 & NA \\
\hline & & Enteric drainage $(n=70)$ & NA & NA & $74^{*}$ & 92 & NA \\
\hline \multirow{2}{*}{$\begin{array}{l}\text { Kuo et al. } 1997 \\
(26)\end{array}$} & \multirow[t]{2}{*}{$2 b$} & Bladder drainage $(n=23)$ & $52 / 23^{\S}$ & 0 & 91 & 96 & 87 \\
\hline & & Enteric drainage $(n=23)$ & $25 / 23$ & 0 & 88 & 100 & 83 \\
\hline \multirow{2}{*}{$\begin{array}{l}\text { Pearson et al. } 1997 \\
\text { (27) }\end{array}$} & \multirow[t]{2}{*}{$2 b$} & Bladder drainage $(n=55)$ & 75 & 6 & 78 & 95 & \\
\hline & & Enteric drainage $(n=11)$ & 0 & 10 & 91 & 100 & \\
\hline
\end{tabular}

$\S$ UTI.

*Statistical significance $(p<0.05)$.

Table 3: Studies on portal drainage versus systemic drainage in SPK

\begin{tabular}{|c|c|c|c|c|c|c|c|}
\hline $\begin{array}{l}\text { Author, } \\
\text { year }\end{array}$ & Level & Number of patients & $\begin{array}{l}\text { Pancreas } \\
\text { thrombosis } \\
\text { rate }(\%)\end{array}$ & $\begin{array}{l}\text { Surgical } \\
\text { complications } \\
(\%)\end{array}$ & $\begin{array}{l}\text { Graft } \\
\text { survival } \\
\text { rate (\%) }\end{array}$ & $\begin{array}{l}\text { Patient } \\
\text { survival } \\
\text { rate (\%) }\end{array}$ & $\begin{array}{l}\text { Rejection } \\
\text { rate } \\
(\%) \\
\end{array}$ \\
\hline \multirow{2}{*}{$\begin{array}{l}\text { Stratta et al. } 2001 \\
\text { (14) }\end{array}$} & \multirow[t]{2}{*}{$1 b$} & Systemic drainage $(n=27)$ & 7 & 30 & 74 & 93 & 33 \\
\hline & & Portal drainage $(n=27)$ & 4 & $26^{\ddagger}$ & 85 & 96 & 33 \\
\hline \multirow{2}{*}{$\begin{array}{l}\text { Petruzzo et al. } 2000 \\
\text { (15) }\end{array}$} & \multirow[t]{2}{*}{$1 b$} & Systemic drainage $(n=17)$ & 6 & 35 & 76 & 88 & 29 \\
\hline & & Portal drainage $(n=17)$ & 6 & $18^{\dagger}$ & 76 & 94 & 29 \\
\hline \multirow{2}{*}{$\begin{array}{l}\text { Philosophe et al. } 2001 \\
\text { (16) }\end{array}$} & \multirow[t]{2}{*}{$2 b$} & Systemic drainage $(n=63)$ & NA & NA & 76 & NA & 45 \\
\hline & & Portal drainage $(n=54)$ & NA & NA & 74 & NA & $9 *$ \\
\hline
\end{tabular}

One-year survival rates.

* Statistical significance $(p<0.05)$.

†Surgical complications.

¥Early relaparotomy.

Table 4: Studies on systemic bladder drainage versus portal enteric drainage in SPK

\begin{tabular}{|c|c|c|c|c|c|c|c|}
\hline Authors & Level & Number of Patients & $\begin{array}{l}\text { Urological } \\
\text { complications } \\
(\%)\end{array}$ & $\begin{array}{l}\text { Pancreas } \\
\text { leakage } \\
(\%)\end{array}$ & $\begin{array}{l}\text { Graft } \\
\text { Survival } \\
\text { rate (\%) }\end{array}$ & $\begin{array}{l}\text { Patient } \\
\text { Survival } \\
\text { rate (\%) }\end{array}$ & $\begin{array}{l}\text { Rejection } \\
\text { rate (\%) }\end{array}$ \\
\hline \multirow{2}{*}{$\begin{array}{l}\text { Gaber et al. } 1995 \\
\text { (17) }\end{array}$} & \multirow[t]{2}{*}{$2 b$} & Systemic bladder drainage $(n=28)$ & 89 & 4 & 75 & 89 & 7 \\
\hline & & Portal enteric drainage $(n=19)$ & $26^{*}$ & 0 & 74 & 88 & 0 \\
\hline \multirow{2}{*}{$\begin{array}{l}\text { Newell et al. } 1996 \\
\text { (18) }\end{array}$} & \multirow[t]{2}{*}{$2 b$} & Systemic bladder drainage $(n=12)$ & 50 & 0 & 83 & 100 & 50 \\
\hline & & Portal enteric drainage $(n=12)$ & 25 & 0 & 83 & 83 & 67 \\
\hline \multirow{2}{*}{$\begin{array}{l}\text { Nymann et al. } 1998 \\
\text { (19) }\end{array}$} & \multirow[t]{2}{*}{$2 b$} & Systemic bladder drainage $(n=30)$ & & NA & 70 & 90 & $63 / 20$ \\
\hline & & Portal enteric drainage $(n=17)$ & & NA & 82 & 82 & $47 / 6^{\dagger}$ \\
\hline \multirow{2}{*}{$\begin{array}{l}\text { Cattral et al. } 2000 \\
(20)\end{array}$} & \multirow[t]{2}{*}{$2 b$} & Systemic bladder drainage $(n=20)$ & 40 & NA & 95 & 95 & 37 \\
\hline & & Portal enteric drainage $(n=20)$ & 20 & NA & 100 & 100 & 15 \\
\hline \multirow{2}{*}{$\begin{array}{l}\text { Stratta et al. } 2000 \\
\text { (14) }\end{array}$} & \multirow[t]{2}{*}{$2 b$} & Systemic bladder drainage $(n=16)$ & NA & NA & 82 & 91 & 44 \\
\hline & & Portal enteric drainage $(n=16)$ & & & 92 & 92 & 31 \\
\hline
\end{tabular}

* Statistical significance $(p<0.05)$.

${ }^{\dagger}$ Patients with rejection/irreversible rejection.

amylase, but complications like urinary tract infections in up to $62 \%$ of bladder-drained patients remained a significant clinical problem (24). With the introduction of new immunosuppressive agents like tacrolimus and mycophenolate mophetil (MMF), the rejection rate dropped and enteric drainage was used again increasingly (24).
No RCT comparing bladder versus enteric drainage technique was identified; therefore the analysis was based on six retrospective studies ranked level 2b (Table 2) (2227). Studies designed to compare systemic bladder with portal enteric drainage were analyzed separately (see below). The pooled number of patients in the six trials was 
Pancreas Transplantation

Table 5: Studies on induction therapy

\begin{tabular}{|c|c|c|c|c|c|c|}
\hline $\begin{array}{l}\text { Author, } \\
\text { year }\end{array}$ & Level & Immunosuppression & $\begin{array}{l}\text { Number of } \\
\text { patients }\end{array}$ & $\begin{array}{l}\text { Graft } \\
\text { survival } \\
\text { rate (\%) }\end{array}$ & $\begin{array}{l}\text { Patient } \\
\text { survival } \\
\text { rate }(\%)\end{array}$ & $\begin{array}{l}\text { Rejection } \\
\text { rate }(\%)\end{array}$ \\
\hline Cantarovich et al. 1998 & $1 b$ & CyA/AZA/steroids & $\mathrm{n}=25$ & 86 & 96 & 76 \\
\hline (30) & & ATG/CyA/AZA/steroids & $n=25$ & 86 & 92 & $36^{*}$ \\
\hline Stratta et al. 2003 & $1 b$ & Daclizumab $(5$ × 1 mg/kg) & $n=107$ & 86 & 98 & 17 \\
\hline \multirow[t]{2}{*}{ (39) } & & Daclizumab $(2 \times 2 \mathrm{mg} / \mathrm{kg})$ & $\mathrm{n}=112$ & 87 & 96 & 15 \\
\hline & & No induction & $\mathrm{n}=78$ & 90 & 99 & $26^{*}$ \\
\hline Burke et al. 2004 & $1 b$ & Induction (any)/FK/MMF/steroids & $n=87$ & $80 \ddagger$ & 97 & 20 \\
\hline (32) & & No induction/FK/MMF/steroids & $\mathrm{n}=87$ & 80 & 94 & $26^{*}$ \\
\hline Kaufmann et al. 2000 & $2 b$ & Daclizumab/FK/MMF/steroids & $n=33$ & 84 & 93 & 6 \\
\hline (23) & & FK/MMF/steroids & $N=17$ & 94 & 100 & 24 \\
\hline Bruce et al. 2001 & $2 b$ & DAC (4-5 doses) & 45 & 98 & 92 & 24 \\
\hline (35) & & DAC (1-3 doses) & 26 & 96 & 92 & $45^{*}$ \\
\hline
\end{tabular}

* Statistical significance $(p<0.05)$.

$\ddagger 3$ years.

Table 6: Studies on calcineurininhibitors

\begin{tabular}{|c|c|c|c|c|c|c|}
\hline $\begin{array}{l}\text { Author, } \\
\text { year }\end{array}$ & Level & Immunosuppression & $\begin{array}{l}\text { Number of } \\
\text { patients }\end{array}$ & $\begin{array}{l}\text { Graft } \\
\text { survival } \\
\text { rate (\%) }\end{array}$ & $\begin{array}{l}\text { Patient } \\
\text { survival } \\
\text { rate (\%) }\end{array}$ & $\begin{array}{l}\text { Rejection } \\
\text { rate }(\%)\end{array}$ \\
\hline Stegall et al. 1997 & \multirow[t]{3}{*}{$1 b$} & Tacrolimus/MMF & 18 & 100 & 100 & 11 \\
\hline \multirow{2}{*}{ (28) } & & CyA/MMF & 18 & 100 & 100 & 11 \\
\hline & & CyA/AZA & 18 & 89 & 100 & $77^{*}$ \\
\hline \multirow{5}{*}{$\begin{array}{l}\text { Bechstein et al. } 2004 \\
\text { (31) } \\
\text { Gruessner et al. } 1996 \\
\text { (33) }\end{array}$} & \multirow[t]{2}{*}{$1 b$} & Induction/MMF steroids/Cy A & 102 & 76 & 97 & 38 \\
\hline & & Induction/MMF steroids/tacrolimus & 103 & $91^{*}$ & 98 & $27^{*}$ \\
\hline & \multirow[t]{3}{*}{$2 b$} & TAC/AZA/steroids & 75 & 87 & 90 & 35 \\
\hline & & CyA/AZA/steroids & 75 & $70^{*}$ & NA & NA \\
\hline & & & & 0.04 & & \\
\hline
\end{tabular}

*Statistical significance $(p<0.05)$.

Table 7: Studies on anti-proliferative agents

\begin{tabular}{|c|c|c|c|c|c|c|}
\hline $\begin{array}{l}\text { Author, } \\
\text { year }\end{array}$ & Level & Immunosuppression & $\begin{array}{l}\text { Number of } \\
\text { patients }\end{array}$ & $\begin{array}{l}\text { Graft } \\
\text { survival } \\
\text { rate (\%) }\end{array}$ & $\begin{array}{l}\text { Patient } \\
\text { survival } \\
\text { rate (\%) }\end{array}$ & $\begin{array}{l}\text { Rejection } \\
\text { rate }(\%)\end{array}$ \\
\hline $\begin{array}{l}\text { Odorico et al. } 1998 \\
\text { (34) }\end{array}$ & $2 b$ & $\begin{array}{l}\text { MMF } \\
\text { AZA }\end{array}$ & $\begin{array}{l}109 \\
249\end{array}$ & $\begin{array}{l}95 \\
83^{*} \\
\text { (2 year) }\end{array}$ & $\begin{array}{l}99 \\
95\end{array}$ & $\begin{array}{l}7 \\
24^{*}\end{array}$ \\
\hline $\begin{array}{l}\text { Stegall et al. } 1997 \\
(28)\end{array}$ & $1 b$ & $\begin{array}{l}\text { Tacrolimus / MMF } \\
\text { CyA / MMF } \\
\text { CyA / AZA }\end{array}$ & $\begin{array}{l}18 \\
18 \\
18\end{array}$ & $\begin{array}{l}100 \\
100 \\
89\end{array}$ & $\begin{array}{l}100 \\
100 \\
100\end{array}$ & $\begin{array}{l}11 \\
11 \\
77^{*}\end{array}$ \\
\hline $\begin{array}{l}\text { Merion et al. } 2000 \\
\text { (29) }\end{array}$ & $1 b$ & $\begin{array}{l}\text { MMF } \\
\text { AZA }\end{array}$ & $\begin{array}{l}74 \\
76\end{array}$ & $\begin{array}{l}85 \\
85\end{array}$ & $\begin{array}{l}93 \\
95\end{array}$ & $\begin{array}{l}27 \\
39\end{array}$ \\
\hline
\end{tabular}

* Statistical significance $(p<0.05)$.

700 in the bladder-drained group and 327 in the entericdrained group. The smallest number of patients in a study was 11 and the largest 388. One-year pancreas graft survival ranged from $78 \%$ to $94 \%$ in the bladder versus $74 \%$ to $93 \%$ in the enteric drainage group. There was no statistical difference regarding graft survival between the two techniques in five studies $(22,23,25-27)$. One study by Sollinger et al. (24) reported a significantly improved 1 -year pancreas graft survival in the bladder group: $82 \%$ in the bladder group ( $n=136$ ) vs. $74 \%$ in the enteric group $(n=70)$, $(p=0.03)$. However, patient survival data re- vealed no differences ranging from $92 \%$ to $100 \%$ in both groups.

Among these six studies (22-27), the urinary tract infection rates ranged from $48 \%$ to $75 \%$ in bladder versus $12 \%$ to $37 \%(26,27)$ in enteric drainage groups ( $p=$ $0.0001)(27)$. Moreover, in two trials $(22,24)$, the urological complication rates were significantly higher in the bladder drainage group compared to the enteric drainage group (62\% vs. $12 \%, p=0.0001$ and $63 \%$ vs. $20 \%, p=0.0001)$, respectively. 
Pancreas leakage was reported in four studies $(22,24,26,27)$ and was significantly lower for enteric drainage ( $5 \%$ vs. $12 \%, p=0.06)$ in one report (22). In the three others $(24,26,27)$, Kuo et al. (26) did not find any leakage; Sollinger et al. (24) reported $17 \%$ in the bladder versus $5 \%$ in the enteric group, and Pearson et al. (27) $6 \%$ in the bladder versus $10 \%$ in the enteric group, without statistical significance. Two trials $(22,24)$ assessed the rate of opportunistic infections, which were significantly lower in the enteric group; opportunistic infection: 12\% versus $33 \%, p=0.002$ (24); and $15 \%$ versus $28 \%$, $\mathrm{p}=0.03(22)$.

The rejection rate was assessed in three trials $(23,24,26)$ disclosing a large variability of rejection rates ranging between $16 \%$ and $87 \%$ depending on the immunological era in which the trial was performed. However, within the trials there was no difference between the two different types of drainage regarding rejection rate as reported by Sollinger et al. (24), who found a $45 \%$ rejection rate in the bladder group versus $39 \%$ in the enteric group at 1 year.

It can be concluded that the use of primary enteric drainage reduced the incidence of urological complications, pancreas leaks and opportunistic infections, without increase in abdominal complications. The analyzed studies reported no differences in graft survival rate between the two different techniques. The analysis favors enteral drainage at a recommendation level grade $\mathrm{B}$. According to the IPTR data (8), a majority of centers currently performs enteric drainage. For example, out of 5650 SPK transplantations performed between 1996 and 2002, 66\% have been performed with enteric drainage technique.

\section{What is the optimal venous drainage? Portal or systemic venous drainage?}

The idea behind portal venous delivery of insulin relies on the concept of avoiding potential complications related to the release of insulin directly into the systemic circulation with associated hyperinsulinemia leading to accelerated arteriosclerosis and dyslipidemia. While some experimental models have suggested a benefit for portal drainage of insulin (37), convincing evidence is still lacking in the clinical setting (38).

Three trials (14-16) analyzed the outcome of venous drainage technique in enteric-drained patients. Two of them $(14,15)$ were RCT ranked level $1 b$, and one was a retrospective study ranked as level $2 a$ (16) (Table 3). The pooled number of patients in the portal group was 107 versus 98 in the systemic group. The 1-year graft survival rates were comparable between both groups ranging from $74 \%$ to $76 \%$ in the systemic drained group and from $74 \%$ to $85 \%$ in the portal drained group.

The venous thrombosis rate in the graft ranged from $4 \%$ to $7 \%$ without differences between the two drainage tech- niques. There was a trend toward lower surgical complication rates (early laparotomy/bleeding/leakage) in the portal group (18-26\% vs. 30-35\%).

The rejection rate was similar in the two RCT $(14,15)$ ranging from $29 \%$ to $33 \%$. Philosophe et al. (16) analyzed a large cohort of patients with the same immunosuppression protocol $(n=117)$ and observed a $9 \%$ rejection rate in the portal group compared to $45 \%$ in the systemic drained group ( $p=0.0002$ ). In the same trial, 97 other patients with pancreas after kidney transplantation were assessed as well. The rejection rate was $16 \%$ in the portal versus $65 \%$ in the systemic drained group $(p=0.0001)$. Moreover, rejections were milder in the portal group in both SPK and pancreas after kidney transplantation. On the other hand, the rejection rate in the systemic group of this retrospective analysis (16) is high compared to those observed in the $\operatorname{RCT}(14,15)$ which makes the benefit of portal drainage on rejection questionable.

In the two prospective studies $(14,15)$, one shows a trend toward lower surgical complication rates observed in the portal drainage groups (4/17 vs.7/17) (15), and the other a trend toward lower intra-abdominal infections (11\% vs. $26 \%$ ) (14). The retroperitoneal approach necessary for systemic drainage, but not for portal drainage, may explain these observations.

Glycamia control is excellent in both techniques, but after portal drainage less hyperinsulinemia was observed in two retrospective studies including 100 and 60 patients, respectively $(17,20)$.

Based on the available data gathered from small series, it can be concluded that portal venous drainage provides only a marginal advantage over systemic drainage. Only trends were documented for lower complication and infection rates favoring portal venous drainage and there were no differences in graft survival. The better insulinemia control was observed only in retrospective studies. This makes a definitive recommendation difficult, but the choice of portal drainage may be suggested. (grade of recommendation $\mathrm{C}$ ).

According to IPTR data, only $23 \%$ of reporting centers (including our own center) performed pancreas transplantation using a portal drainage in 2003 (8). However, despite the relatively small number of transplant centers performing a portal venous drainage, a center more than a technique effect is unlikely to explain the improved results of portal over systemic drainage, and further RCT are needed.

\section{Which combination of venous and exocrine drainage should be selected?}

From the various possible combinations of venous and exocrine drainage, data are available only in patients treated 
with systemic venous bladder exocrine versus portal venous enteric exocrine drainage.

Systemic bladder drainage was compared to portal-enteric drainage in five studies $(14,17-20)$. The total pooled number of patients was 106 in the systemic-bladder drainage group and 84 in the portal-enteric drainage group. There was no statistically significant difference at 1 year in terms of graft (range: $70-100 \%$, irrespective of the group) and patient (range: 82-100\%) survival rates.

Gaber et al. (17) reported less urinary tract infections in the enteric drainage group in their series of 115 patients (89\% vs. $26 \%, p<0.0001$ ). However, all other trials (1821) failed to show a significant reduction of urinary tract infections in the enteric group (Table 2). Pancreas leakage was only assessed in two trials $(17,19)$ showing comparable rates, that is, $0-4 \%$ in the systemic bladder versus $0-6 \%$ in the portal enteric group. Sollinger et al. (24) reported a conversion rate of $24 \%(n=388)$ from bladder to enteric drainage at 5 year due to urological complications.

There were no differences in rejection rates among the five trials $(14,17-20)$. Two studies $(17,20)$ reported lower rates of acidosis in the portal enteric group reaching statistically significant values in one trial $(75 \%$ vs. $8 \%, p<0.005)(20)$. The same studies $(17,20)$ reported less hyperinsulinemia in the portal compared to systemic drainage groups with significant lower fasting insulin levels (11.0 vs. $55.3 \mathrm{U} / \mathrm{mL}$; $\mathrm{p}=0.01)(17)$

The benefit of combined portal and enteric drainage appears to be related mostly to lower urological complication rates than to better controls of rejection or diabetes and this appears mainly due to the enteric drainage, while the impact of portal drainage remains difficult to evaluate. The influence of recently-introduced immunosuppressive protocols, rather than a specific surgical technique, may also have significantly contributed to improved outcome. The failure to measure urine amylase after enteric drainage was not associated with increased rejection rates supporting the input of novel effective immunosuppressive regimens.

We conclude that the combination of portal venous and enteric exocrine drainage seems superior to systemic venous and bladder-drained pancreas. (recommendation grade B).

\section{What is the best immunosuppressive regimen minimizing rejection and improving graft survival?} Induction therapy (Table 5): Five trials $(23,30,32,35,39)$ evaluating induction therapies were identified. Three level $1 \mathrm{~b}$ trials $(30,32,39)$ evaluated the benefit of Daclizumab and ATG versus no-induction therapy. One trial compared T-cell depleting ATG induction therapy versus no-induction therapy in 50 patients who received CyA, azathioprine (AZA) and corticosteroids. One level 1b trial (39) analyzed 219 patients receiving Daclizumab induction therapy intwo different regimens. All studies favored induction therapy with significant reduction of biopsy-proven renal rejection rates from $76 \%$ to $36 \%(p=0.01)(30)$ and reduced pancreas rejection rates (range: $3.6-10.3 \%, p=0.160$ ). The 1 -year graft survival rates of all trials ranged between $84 \%$ and $98 \%$. In the no-induction groups the 1-year graft survival ranged from $86 \%$ to $90 \%$ versus $84 \%$ to $96 \%$ in the induction groups. There were no statistically significant differences between induction versus no-induction therapy regarding graft and patient survival except for 3-year renal graft survival: $92 \%$ versus $82 \%$ in no-induction group $(p=0.04)(32)$

Calcineurin inhibitors (Table 6): One multicenter level $2 b$ (33) and two level 1b $(28,31)$ studies compared the effects of two calcineurin inhibitors, CyA versus tacrolimus. The results of 54 patients receiving either CyA or tacrolimus with MMF were compared to a historical control group ( $n=18$ ) who received a CyA and AZA-based immunosuppression. There was no significant difference between tacrolimus and CyA regarding kidney rejection rates (11\% in each group), but patients receiving either calcineurin inhibitors with MMF had a significant decrease in biopsy-proven kidney rejection rates from $77 \%$ to $11 \%$ ( $p=0.01$ ) (28). A multicenter trial (33) including $150 \mathrm{pa}-$ tients showed a lower graft survival rate in the CyA group (70\%) compared to tacrolimus group (87\%) ( $p=0.04)$. The results of a large multicenter trial published recently by Bechstein et al. (31) with induction MMF, short-term steroids and CyA in 102 and tacrolimus in 103 patients demonstrated a significant lower rejection rate in favor of tacrolimus (27.2\% vs. 38.2\%, p=0.09). One-year pancreas graft survival was significantly higher in tacrolimus group: $91.3 \%$ versus $74.5 \%, p<0.0005$ (31).

Anti-proliferative agents (Table 7): Two RCT $(28,29)$ and one retrospective study (34) analyzed the outcome in patients with AZA in comparison to MMF. All trials suggested a benefit for the use of MMF regarding rejection rates: $7 \%$ versus $24 \%(p<0.05), 11 \%$ versus $77 \%$ ( $p<$ $0.01)$ and $27 \%$ versus $39 \%(p=0.3)$. However, patient survival rates were comparable between the groups ranging from $93 \%$ to $100 \%$. Graft survival was significantly lower for AZA in the retrospective report (34), 83\% versus 95\% in the MMF group ( $<<0.05$ ), whereas the two prospective trials $(28,29)$ showed similar high rates of graft survival irrespective of the immunosuppression ranging between $85 \%$ and $100 \%$.

Corticosteroids: All immunosuppression regimens analyzed above included corticosteroids as basis therapy. However, to prevent long-term side effects of steroid therapy such as hyperglycemia and osteoporosis, there has been an increasing interest in favoring steroid-free multimodal immunosuppressive therapy for pancreas transplantation. The rapid elimination of corticosteroids in SPK was analyzed prospectively in 126 patients (40). 
Corticosteroids were discontinued 6 days after transplantation in 40 patients (29\%). These patients received either tacrolimus and MMF or tacrolimus and sirolimus. Patient and graft survival rates were compared to a historical control group of SPK recipients ( $n=86$ ), who received a quadruple therapy including induction therapy, tacrolimus, MMF and corticosteroids. The rejectionfree survival rate with rapid steroid elimination was $100 \%$ in the tacrolimus/sirolimus group, and $95 \%$ in the tacrolimus/MMF group (collectively $97.5 \%$ ), compared to $80 \%$ in the historical control group ( $p=0.034)$. Corticosteroids still belongs to basis immunosuppression, but early withdrawal seems safe.

From all these studies on immunosuppression, it can be concluded that both calcineurin inhibitors (Cya and tacrolimus) confer similar protection against rejection with a possible benefit in graft survival rates for tacrolimus. MMF is superior to AZA regarding rejection rates, and induction therapy decreases rejection rates and increases graft survival. Rapid corticosteroid elimination appears to be a safe strategy. The use of either calcineurin inhibitor in combination with MMF and induction therapy should be recommended (Recommendation grade $A$ ).

According to IPTR registry data (8), the majority of pancreas transplant centers are using a regimen including an induction therapy, tacrolimus, MMF or derivate and steroids, which is consistent with the evidence-based analysis.

\section{Is simultaneous pancreas kidney transplantation cost-effective?}

We identified four studies assessing different aspects of cost-effectiveness regarding pancreas transplantation (4144). Douzdjian et al. (42) assessed the cost of different treatment strategies for diabetic patients with end-stage renal disease comparing costs associated to dialysis alone, kidney transplant alone (living or cadaver donor) and SPK transplantation. The analysis was based on a 5-year model. The outcome criteria used in the model were cost, utility and cost-utility. The expected cost per quality-adjusted year for each of the treatment strategies in the model were \$317 746 for dialysis, \$156 042 for cadaver kidney transplant, \$123 923 for living kidney transplant and \$102 422 for SPK transplantation. SPK transplantation remained the optimal strategy even with the use of varying survival probabilities, various costs and utilities over plausible ranges by means of one-way sensitivity analysis. With the use of the same 5-year model, this group also analyzed the cost and utility of living kidney alone followed by pancreas transplantation (pancreas after kidney) versus SPK transplantation. The expected 5-year costs were comparable in both groups. When adjusted for utility, living kidney alone followed by pancreas transplantation yielded a cost of $\$ 153911$ and SPK a cost of $\$ 110828$ per quality-adjusted year (42).
Reddy et al. (44) compared the costs of bladder versus enteric drainage in SPK transplantation. Patients with enteric drainage had a $43 \%$ cost reduction in hospital charges compared to bladder drainage, for comparable graft survival rates. A shorter hospital stay and a reduction in drugs, radiology/nuclear medicine and laboratory charges contributed to decrease hospital charges in patients with enteric drainage.

Stratta et al. (41) demonstrated the utility of managedcare principles (care maps) in decreasing the length of stay and clinical laboratory tests, thus stabilizing the hospital charges despite the rising costs of medical care.

The available studies suggest that successful SPK transplantation is cost-effective, and together with a clear increase in quality of life, is superior to alternative treatment strategies such as dialysis, kidney transplant alone and insulin therapy. However, these data are based on charges rather than true costs. True cost analyses are needed to better compare the different therapeutic options. Moreover, it is obvious that these analyses are not based on patients randomized between transplantation and conservative treatment. A bias selection in favor of transplantation may be possible, but beside the better quality of life, all the figures demonstrate the cost-effectiveness of SPK transplantation.

Based on the analysis of the United Network of Organ Sharing (UNOS) data between 1995 and 2000, respectively $(45,46)$, the overall risk of death after SPK transplantation lied between 0.29 and 0.43 compared with patients remaining on the waiting list ( $p<0.001)$.

We conclude that a successful SPK transplantation is costeffective, and together with improved quality of life, is superior to alternative treatment strategies such as dialysis or kidney transplant alone and insulin therapy (recommendation grade $\mathrm{C}$ ).

\section{Is pancreas transplantation alone a viable therapeutic strategy?}

Intensive insulin therapy delays the onset of secondary diabetic complications, but does not substitute for normal beta-cells functions (47). Thus only the replacement by a pancreas allows to restore normal glucose metabolism. For this reason, pancreas transplantation alone has be considered as an option in diabetic patients without nephropathy (48).

There are currently no prospective clinical trials available on pancreas transplantation alone, and most of the data come from the IPTR and UNOS databases $(8,36)$. Gruessner et al. (49) retrospectively assessed the outcome of 225 solitary pancreas recipients within three different immunosuppression eras. Graft survival rates increased from 34\% in the pre-calcineurin inhibitors era to $80 \%$ in the CyA and 
tacrolimus era. Pancreas graft loss due to rejection also decreased from $50 \%$ to $9 \%$. Technical failure rates decreased from $30 \%$ to near $0 \%$. The authors conclude that solitary pancreas transplantation has become a viable alternative for nonuremic patients with labile diabetes mellitus. The same group (46) has recently reported in 647 patients a 4-year survival rate post-transplant of $90.5 \%$ compared to $87.3 \%$ in 1207 patients on the waiting list. These results strongly challenge an other analysis of the same UNOS data published earlier by Venström et al. (45). This group demonstrated an increased risk of mortality for pancreas transplantation alone compared to patients on the waiting list (relative risk of death 1.57, $p<0.001$ ). These discrepancies have several explanations, for example the fact that unlike Europe, U.S. patients are allowed to be on several waiting lists may increase the waiting list and decrease the mortality rate on this waiting list. Moreover, some patients were excluded of the analysis further contributing to an underestimation of the mortality on the waiting list. Nevertheless, even if these points remain debated, the continuously improved outcome of pancreas transplantation alone is a fact, with excellent 4-year survival around $90 \%$.

Using a Markov model, Kiberd et al. (43) compared the outcome and direct health care costs for patients with type 1 diabetes mellitus without nephropathy assigned to either standard insulin therapy or pancreas transplantation alone. Assuming a 10-year baseline pancreas-graft life expectancy, early pancreas transplantation could provide 0.42 more life-years and 2.2 more quality-adjusted life-years compared to patients treated with standard insulin therapy. The incremental costs (charges) for early pancreas transplantation over standard therapy were estimated to be about $\$ 56$ 600/quality-adjusted life-year for the baseline case. Pancreas transplant costs were also a very sensitive parameter in the cost-utility analysis. The authors concluded that a trial in selected type 1 diabetic patients at risk for renal and retinal disease should be considered.

All authors agree on the need to perform a prospective randomized study on pancreas transplantation alone in diabetics with preserved renal function compared to conservative therapy. Until such data become available, we can only recommend pancreas transplantation alone in selected patients (recommendation grade $\mathrm{C}$ ).

\section{Does pancreas transplantation alone reverse diabetic nephropathy?}

Fioretto et al. (48) have shown that prolonged euglycemia provided by pancreas transplantation alone in diabetic patients may reverse diabetic nephropathy. This observation was made in eight patients, who were followed over 10 years after pancreas transplantation alone. Pancreas transplantation could reverse the lesions of diabetic nephropathy, but reversal required more than 5 years of normoglycemia. The beneficial effects were evident despite the
Table 8: Evidence-based pancreas transplantation: grade of recommendation

1. General comment

1.1 Pancreas transplantation currently offers excellent long-term graft function and patient survival rates.

2. Recommendation Grade A

2.1 The choice of an effective immunosuppression regimen is key for success. It should include induction therapy, calcineurin inhibitors, MMF or derivate, and steroids.

3. Recommendation grade $B$

3.1 Enteric exocrine is superior to bladder drainage.

4. Recommendation grade $\mathrm{C}$

4.1 Portal venous drainage might be superior, although insufficient evidence is currently available.

4.2 SPK transplantation is highly cost-effective.

4.3 Pancreas transplantation alone is an emerging therapy with promise in control of several diabetic complications $A$ RCT should specify its real value.

nephrotoxic effects of immunosuppressive agents. On the other hand, Mazur et al. (50) investigated the renal function in 23 patients after pancreas transplantation and showed a decline in the native renal function in the majority of patients regardless of the pre-transplant glomerular filtration rates.

We conclude that pancreas transplantation alone may be cost-effective in selected labile nonuremic diabetics, although the authors failed to show a patient-survival benefit (recommandation grade C). A prospective comparison of the outcome of type 1 diabetic patients with and without pancreas transplantation alone should be performed with special regard to the progression of kidney function.

\section{Concluding Remarks}

Despite the paucity of RCT studies and many low-quality studies on pancreas transplantation, this evidence-based methodology appears to be a valuable tool to suggest recommendations on various surgical and immunological options available.

The present review allows six important statements summarized in Table 8. Except a recommendation A for immunosuppression, the level of evidence for these recommendations and statements is limited to B or C. Despite a few large series with very convincing data $(17,24,25,31,32,51)$, the total number of patients analyzed remains relatively low. We conclude, however, that based on this best available scientific evidence, SPK is currently the gold standard to which other therapies should be compared.

\section{References}

1. Kelly WD, Lillehei RC, Merkel FK, Idezuki Y, Goetz FC. Allotransplantation of the pancreas and duodenum along with the kidney in diabetic nephropathy. Surgery 1967; 61: 827-837. 
2. Lillehei RC, Ruix JO, Aquino C, Goetz F. Transplantation of the pancreas. Acta Endocrinol Suppl (Copenh) 1976; 205: 303-320.

3. Groth C, Lundgren G, Gunnarsson R, Berg B, Arner P, Ostman $J$. Experience with pancreatic transplantation in Stockholm. Acta Med Scand Suppl 1980; 639: 49-54.

4. Ostman J, Arner P, Groth CG, Gunnarsson R, Heding L, Lundgren G. Plasma C-peptide and serum insulin antibodies in diabetic patients receiving pancreatic transplants. Diabetologia 1980; 19: 25-30.

5. Sutherland DE, Goetz FC, Najarian JS. Clinical segmental pancreas transplantation without duct anastomosis in diabetic renal allograft recipients. Diabetes 1980; 29(Suppl 1): 10-18.

6. Cook K, Sollinger HW, Warner T, Kamps D, Belzer FO. Pancreaticocystostomy: an alternative method for exocrine drainage of segmental pancreatic allografts. Transplantation 1983; 35: 634636.

7. Sollinger HW, Kalayoglu M, Hoffman RM, Deierhoi MH, Belzer FO. Quadruple immunosuppressive therapy in whole pancreas transplantation. Transplant Proc 1987; 19(1 Pt 3): 2297-2299.

8. Internation Pancreas Transplant Registry. In: http://www.iptr. umn.edu; 2005.

9. Gruessner AC, Sutherland DE. Pancreas transplant outcomes for United States (US) and non-US cases as reported to the United Network for Organ Sharing (UNOS) and the International Pancreas Transplant Registry (IPTR) as of October 2002. Clin Transpl 2002: 41-77.

10. Shapiro AM, Lakey JR, Ryan EA et al. Islet transplantation in seven patients with type 1 diabetes mellitus using a glucocorticoid-free immunosuppressive regimen. N Engl J Med 2000; 343: 230-238.

11. Center for Evidence-based Medicine. In: http://www.cebm.net; 2005.

12. Meakins JL. Innovation in surgery: the rules of evidence. Am J Surg 2002; 183: 399-405

13. Sackett D, Richardson W. Evidence-based medicine. How to Practise and Teach EBM. Edinburg: Churchill Livingstone, 2000.

14. Stratta RJ, Shokouh-Amiri MH, Egidi MF et al. A prospective comparison of simultaneous kidney-pancreas transplantation with systemic-enteric versus portal-enteric drainage. Ann Surg 2001; 233: 740-751.

15. Petruzzo P, Da Silva M, Feitosa LC et al. Simultaneous pancreaskidney transplantation: portal versus systemic venous drainage of the pancreas allografts. Clin Transplant 2000; 14(4 Pt 1): 287-291.

16. Philosophe B, Farney AC, Schweitzer EJ et al. Superiority of portal venous drainage over systemic venous drainage in pancreas transplantation: a retrospective study. Ann Surg 2001; 234: 689696.

17. Gaber AO, Shokouh-Amiri MH, Hathaway DK et al. Results of pancreas transplantation with portal venous and enteric drainage. Ann Surg 1995; 221: 613-622; discussion 622-624.

18. Newell KA, Bruce DS, Cronin DC et al. Comparison of pancreas transplantation with portal venous and enteric exocrine drainage to the standard technique utilizing bladder drainage of exocrine secretions. Transplantation 1996; 62: 1353-1356.

19. Nymann T, Hathaway DK, Shokouh-Amiri MH et al. Patterns of acute rejection in portal-enteric versus systemic-bladder pancreas-kidney transplantation. Clin Transplant 1998; 12: 175183.

20. Cattral MS, Bigam DL, Hemming AW et al. Portal venous and enteric exocrine drainage versus systemic venous and bladder exocrine drainage of pancreas grafts: clinical outcome of 40 consecutive transplant recipients. Ann Surg 2000; 232: 688-695.

21. Stratta RJ, Gaber AO, Shokouh-Amiri MH et al. A prospective comparison of systemic-bladder versus portal-enteric drainage in vascularized pancreas transplantation. Surgery 2000; 127 : 217226.

22. Pirsch JD, Odorico JS, D'Alessandro AM, Knechtle SJ, Becker $\mathrm{BN}$, Sollinger HW. Post-transplant infection in enteric versus bladder-drained simultaneous pancreas-kidney transplant recipients. Transplantation 1998; 66: 1746-1750.

23. Kaufman DB, Leventhal JR, Koffron A et al. Simultaneous pancreas-kidney transplantation in the mycophenolate mofetil/tacrolimus era: evolution from induction therapy with bladder drainage to noninduction therapy with enteric drainage. Surgery 2000; 128: 726-737.

24. Sollinger HW, Odorico JS, Knechtle SJ, D'Alessandro AM, Kalayoglu M, Pirsch JD. Experience with 500 simultaneous pancreaskidney transplants. Ann Surg 1998; 228: 284-296.

25. Sutherland DE, Gruessner RW, Dunn DL et al. Lessons learned from more than 1000 pancreas transplants at a single institution. Ann Surg 2001; 233: 463-501.

26. Kuo PC, Johnson LB, Schweitzer EJ, Bartlett ST. Simultaneous pancreas/kidney transplantation-a comparison of enteric and bladder drainage of exocrine pancreatic secretions. Transplantation 1997; 63: 238-243.

27. Pearson TC, Santamaria PJ, Routenberg KL et al. Drainage of the exocrine pancreas in clinical transplantation: comparison of bladder versus enteric drainage in a consecutive series. Clin Transplant 1997; 11: 201-205.

28. Stegall MD, Simon M, Wachs ME, Chan L, Nolan C, Kam I. Mycophenolate mofetil decreases rejection in simultaneous pancreas-kidney transplantation when combined with tacrolimus or cyclosporine. Transplantation 1997; 64: 1695-1700.

29. Merion RM, Henry ML, Melzer JS, Sollinger HW, Sutherland DE, Taylor RJ. Randomized, prospective trial of mycophenolate mofetil versus azathioprine for prevention of acute renal allograft rejection after simultaneous kidney-pancreas transplantation. Transplantation 2000; 70: 105-111.

30. Cantarovich D, Karam G, Giral-Classe M et al. Randomized comparison of triple therapy and anti-thymocyte globulin induction treatment after simultaneous pancreas-kidney transplantation. Kidney Int 1998; 54: 1351-1356.

31. Bechstein WO, Malaise J, Saudek F et al. Efficacy and safety of tacrolimus compared with cyclosporine microemulsion in primary simultaneous pancreas-kidney transplantation: 1-year results of a large multicenter trial. Transplantation 2004; 77: 12211228.

32. Burke GW, 3rd, Kaufman DB, Millis JM et al. Prospective, randomized trial of the effect of antibody induction in simultaneous pancreas and kidney transplantation: three-year results. Transplantation 2004; 77: 1269-1275.

33. Gruessner RW, Burke GW, Stratta R et al. A multicenter analysis of the first experience with FK506 for induction and rescue therapy after pancreas transplantation. Transplantation 1996; 61: 261-273.

34. Odorico JS, Pirsch JD, Knechtle SJ, D'Alessandro AM, Sollinger HW. A study comparing mycophenolate mofetil to azathioprine in simultaneous pancreas-kidney transplantation. Transplantation 1998; 66: 1751-1759.

35. Bruce DS, Sollinger HW, Humar A et al. Multicenter survey of daclizumab induction in simultaneous kidney-pancreas transplant recipients. Transplantation 2001; 72: 1637-1643.

36. United Network for Organ Sharing. Available at: http://www. cebm.net; 2005.

37. Kissler HJ, Hennig R, Gepp H, Hohenberger W, Schwille PO. The solution to hyperglucagonemia after pancreas transplantation in inbred rats. Eur Surg Res 2001; 33: 370-376. 
Pancreas Transplantation

38. Petruzzo $P$, Laville $M$, Badet $L$ et al. Effect of venous drainage site on insulin action after simultaneous pancreas-kidney transplantation. Transplantation 2004; 77: 1875-1879.

39. Stratta RJ, Alloway RR, Lo A, Hodge E. Two-dose daclizumab regimen in simultaneous kidney-pancreas transplant recipients: primary endpoint analysis of a multicenter, randomized study. Transplantation 2003; 75: 1260-1266.

40. Kaufman DB, Leventhal JR, Koffron AJ et al. A prospective study of rapid corticosteroid elimination in simultaneous pancreaskidney transplantation: comparison of two maintenance immunosuppression protocols: tacrolimus/mycophenolate mofetil versus tacrolimus/sirolimus. Transplantation 2002; 73: 169-177.

41. Stratta RJ, Cushing KA, Frisbie K, Miller SA. Analysis of hospital charges after simultaneous pancreas-kidney transplantation in the era of managed care. Transplantation 1997; 64: 287-292.

42. Douzdjian V, Escobar F, Kupin WL, Venkat KK, Abouljoud MS. Cost-utility analysis of living-donor kidney transplantation followed by pancreas transplantation versus simultaneous pancreas-kidney transplantation. Clin Transplant 1999; 13(1 Pt 1): 51-58.

43. Kiberd BA, Larson T. Estimating the benefits of solitary pancreas transplantation in nonuremic patients with type 1 diabetes mellitus: a theoretical analysis. Transplantation 2000; 70: 1121-1127.

44. Reddy KS, Johnston TD, Karounas D, Ranjan D. Hospital charges following simultaneous kidney-pancreas transplantation: enteric drainage versus bladder drainage. Clin Transplant 2000; 14(4 Pt 2): 375-379.
45. Venstrom JM, McBride MA, Rother KI, Hirshberg B, Orchard TJ, Harlan DM. Survival after pancreas transplantation in patients with diabetes and preserved kidney function. Jama 2003; 290: $2817-$ 2823.

46. Gruessner RW, Sutherland DE, Gruessner AC. Mortality assessment for pancreas transplants. Am J Transplant 2004; 4: 20182026.

47. The effect of intensive treatment of diabetes on the development and progression of long-term complications in insulindependent diabetes mellitus. The Diabetes Control and Complications Trial Research Group. N Engl J Med 1993; 329: 977986.

48. Fioretto P, Steffes MW, Sutherland DE, Goetz FC, Mauer M. Reversal of lesions of diabetic nephropathy after pancreas transplantation. N Engl J Med 1998; 339: 69-75.

49. Gruessner RW, Sutherland DE, Najarian JS, Dunn DL, Gruessner AC. Solitary pancreas transplantation for nonuremic patients with labile insulin-dependent diabetes mellitus. Transplantation 1997; 64: 1572-1577.

50. Mazur MJ, Rea DJ, Griffin MD et al. Decline in native renal function early after bladder-drained pancreas transplantation alone. Transplantation 2004; 77: 844-749.

51. Stratta RJ, Shokouh-Amiri MH, Egidi MF et al. Long-term experience with simultaneous kidney-pancreas transplantation with portal-enteric drainage and tacrolimus/mycophenolate mofetilbased immunosuppression. Clin Transplant 2003; 17(Suppl 9): 69-77. 